\title{
COVID-19: how a self-monitoring checklist can empower early intervention and slow disease progression
}

\author{
Christopher L. Cummings ${ }^{1}$ (1) $\cdot$ Craig S. Miller $^{2}$
}

Accepted: 20 February 2021 / Published online: 8 March 2021

(c) The Author(s), under exclusive licence to Springer Science+Business Media, LLC, part of Springer Nature 2021

\begin{abstract}
The SARS-CoV-2 novel coronavirus pandemic has revealed many scientific, social, and institutional challenges required to improve the health and wellbeing of individuals stricken by this disease. While organizations and governing institutions have risen to the task to concurrently prepare for and respond to this pandemic under conditions of high uncertainty and extreme pressure, another important aspect of this viral infection deserves attention and is not being fully considered, that is early intervention strategies and structured tools for individuals who test positive for the virus and begin developing symptoms. For those whose infection is progressing, we describe the potential benefits of a self-monitoring tool for use in combination with physician directed early medical interventions to slow COVID-19 progression.
\end{abstract}

Keywords COVID-19 $\cdot$ Risk $\cdot$ Early intervention $\cdot$ Risk response

\section{Introduction}

To date, there have been more than 110 million COVID19 cases worldwide culminating in more than 2.4 million deaths (WHO 2021). This global pandemic has strained public health infrastructures around the world and revealed many scientific, social, and institutional challenges required to improve the health and wellbeing of individuals stricken by this disease (Smith and Fraser 2020; Wells et al. 2021). Organizations and governing institutions have risen to the task to concurrently prepare for and respond to this pandemic under conditions of high uncertainty and extreme pressure. Their efforts to enact 'real-time anticipatory responses' to assess COVID-19 risks, model future disease scenarios of potential crisis conditions, and facilitate large-scale organizational responses during this crisis is exemplary (see Hynes

Christopher L. Cummings

christopherlcummings@gmail.com

Craig S. Miller

craig.miller@uky.edu

1 Genetic Engineering and Society, Senior Research Fellow, North Carolina State University and Gene Edited Foods Project, Iowa State University, Iowa, USA

2 Professor and Chief, Division of Oral Diagnosis, Oral Medicine and Maxillofacial Radiology, College of Dentistry, University of Kentucky, Kentucky, USA et al. 2020; Trump et al. 2020; Wells et al. 2021). Government agencies and news outlets have done a commendable job to enact responsive and effective risk communication by focusing attention on public safety measures, the effects of the pandemic on businesses and the economy, vaccine development and roll-out, as well as the morbidity, hospitalizations, and mortality associated with COVID-19 progression (Abrams and Greenhawt 2020). However, another important aspect of this viral infection deserves attention and is not being fully considered, that is early intervention strategies and structured tools for individuals who test positive for the virus and begin developing symptoms. For those whose infection is progressing, we describe the potential benefits of a self-monitoring tool for use in combination with physician directed early medical interventions to slow COVID-19 progression.

The United States Centers for Disease Control and Prevention (CDC), states if you are sick with COVID-19, "Stay in touch with your doctor" and "Be sure to get care if you have trouble breathing, or have any other emergency warning signs such as persistent pain or pressure in the chest, new confusion, inability to wake or stay awake, bluish lips or face" (CDC 2019a). In addition, the CDC provides clinical guidance for the management of patients with confirmed COVID-19 infection, which alerts clinicians to greater risk of progression after 5 days of no improvement (CDC 2019b). 
However, is this enough to effectively reduce severe outcomes and the demand on the healthcare system?

The public would be better served if coordinated health messaging advised people how to recognize a worsening COVID-19 infection, especially before it develops into an emergency. Common medical practice demonstrates that early intervention of microbial infections results in better outcomes than allowing such infections to progress. To date, there is some information on early intervention regarding COVID infection but few calls for early treatment options (Goyal et al. 2020; Kim et al. 2020; McCullough et al. 2020). More can, and should be done. One promising option would be the creation and widespread dissemination of a structured tool, i.e., a checklist, that will better inform individuals on how to self-monitor their infection when symptoms develop.

Such a checklist should provide simple and direct criteria to COVID-positive individuals regarding when to stay home and nurse their infection versus when signs and symptoms indicate disease progression and warrant specific early interventions prior to the need for emergency medical treatment for life-threatening disease.

This checklist should provide quick and helpful empirical criteria that COVID-positive individuals can use to selfmonitor. It should be designed to provide a handful of key signs and symptoms based on empirical data that suggest that the infection is progressing or likely to progress, and outpatient treatment should be provided. For example, the following manifestations could be considered for inclusion on the checklist ${ }^{1}$ :

- Fever (100 degrees F or higher) for 3 or more days, with

- Shortness of breath,

- Chest pain, pressure or tightness,

- Oxygen saturation of $94 \%$ or less

- Bluish lips or face

- Inability to wake or stay awake

These features in combination with a predisposing condition such as those listed by the CDC (age, cancer, chronic kidney disease, chronic obstructive pulmonary disease, heart conditions such as heart failure, coronary artery disease, or cardiomyopathies, obesity, severe obesity, sickle cell anemia, smoking, and Type 2 diabetes mellitus) would allow for a simple scoring method to identify those at greater risk (CDC 2019c). Such scoring tools have been successfully used for screening and early intervention in a variety of health conditions ranging from malnutrition to asthma and even sexually transmitted infections (Power et al. 2019). The checklist could be self-administered or used in conjunction

\footnotetext{
${ }^{1}$ Such a tool requires obligatory accuracy, validity, and reliability analyses
}

with healthcare professionals when communicating with infected persons and could be posted as public service announcements to inform the public so better and earlier risk decisions are made. In this scenario, portable pulse oximeters could be made available to checkout at no cost through community resources, such as the public library system or corporate, community and local healthcare entities, to improve at home measures and self-monitoring.

A COVID-19 infected person who fulfills the checklist criteria or has a certain score above a specific threshold would be advised to contact their health provider to receive early intervention. These treatments would require evidencebased findings but could involve inexpensive approaches including readily available nutraceuticals (e.g., vitamin D) (Mercola et al. 2020; Di Renzo et al. 2020) or drugs such as antimicrobial and anti-inflammatory agents (Firth and Prathapan 2020; Oldenburg and Doan 2020; Padhy et al. 2020), oxygen supplementation (Long et al. 2021), and personal monitoring devices like pulse oximeters (McCullough et al. 2020). Through such simple and early interventions we may mitigate some disease progressions that would otherwise result in hospitalization and even death.

We are now amidst the vaccine roll-out and concurrently experiencing the spread of viral variants that bring into question the long-lasting efficacy of the vaccine. Secondary risk perceptions of vaccines (Cummings et al. 2020) may also prompt increased vaccine hesitancy thus contributing to continued incidence and prevalence of infection over coming months if not years, especially in resource poor regions. Thus, 'early diagnosis and early intervention' will remain topics worthy of discussion and warrant our clinician-scientists attention. For those focused on this issue, it remains critically important to ask questions like 'what factors suggest disease progression', 'can the public be made more aware of these features', and 'what early interventional treatments could benefit the public the most'?

While a structured tool certainly would have helped during 2020, now is a good time to add a simple and practical checklist that represents a key pivot to our management of COVID-19. As we continue to evolve our risk messaging to incorporate our best understanding of this disease and treatment, a simple checklist may help hundreds of thousands of people receive earlier intervention, improve outcomes, and improve the resilience of our public health infrastructure.

\section{References}

Abrams EM, Greenhawt M (2020) Risk communication during COVID-19. J Allergy Clin Immunol Pract 8(6):1791

CDC (2019a). Symptoms of coronavirus. Centers for disease control and prevention. https://www.cdc.gov/coronavirus/2019-ncov/ symptoms-testing/symptoms.html\#seek-medical-attention. Accesses 27 Oct 2020. 
CDC (2019b). Interim clinical guidance for management of patients with confirmed coronavirus disease. https://www.cdc.gov/coron avirus/2019-ncov/hcp/clinical-guidance-management-patients. html. Accessed 27 Oct 2020.

CDC (2019c). People with certain medical conditions. Centers for disease control and prevention. https://www.cdc.gov/coronaviru s/2019-ncov/need-extra-precautions/people-with-medical-condi tions.html. Accessed 27 Oct 2020.

Cummings C, Rosenthal S, Kong WY (2020) Secondary risk theory: validation of a novel model of protection motivation. Risk Anal 41(1):204-220. https://doi.org/10.1111/risa.13573

Di Renzo L, Gualtieri P, Pivari F, Soldati L, Attinà A, Leggeri C, Cinelli G, Tarsitano MG, Caparello G, Carrano E, Merra G, Pujia AM, Danieli R, De Lorenzo A.J (2020) COVID-19: is there a role for immunonutrition in obese patient? Transl Med 18(1):415. https ://doi.org/10.1186/s12967-020-02594-4

Firth A, Prathapan P, Azithromycin (2020) The first broad-spectrum therapeutic. Eur J Med Chem 207:112739. https://doi. org/10.1016/j.ejmech.2020.112739

Goyal DK, Mansab F, Iqbal A, Bhatti S (2020) Early intervention likely improves mortality in COVID-19 infection. Clin Med 20(3):248-250

Hynes W, Trump B, Love P, Linkov I (2020) Bouncing forward: a resilience approach to dealing with COVID-19 and future systemic shocks. Environ Syst Decis 40: 174-184

Kim P et al (2020) Therapy for early COVID-19 - a critical need. J Am Med Assoc. https://doi.org/10.1001/jama.2020.22813

Long L, Wu L, Chen L et al (2021) Effect of early oxygen therapy and antiviral treatment on disease progression in patients with COVID-19: a retrospective study of medical charts in China. PLoS Neglect Trop Dis 15(1):e0009051. https://doi.org/10.1371/ journal.pntd.0009051
McCullough P, Alexander P, Armstrong R et al (2020) Multifaced highly targeted sequential multidrug treatment of early ambulatory high-risk SARS-CoV-2 infection (COVID-19). Rev Cardiovasc Med 21(4):517-530. https://doi.org/10.31083/j.rcm.2020.04.264

Mercola J, Grant WB, Wagner CL (2020) Evidence regarding vitamin $\mathrm{D}$ and risk of COVID-19 and its severity. Nutrients 12(11):3361. https://doi.org/10.3390/nu12113361 (PMID: 33142828)

Oldenburg C, Doan T. Azithromycin for severe COVID-19 . Lancet 2. https://doi.org/10.1016/S0140-6736(20)31863-8

Padhy BM, Mohanty RR, Das S, Meher BR (2020) Therapeutic potential of ivermectin as add on treatment in COVID 19: a systematic review and meta-analysis. J Pharm Pharm Sci. 23:462-469. https ://doi.org/10.18433/jpps31457 (PMID: 33227231)

Power L, de van der Schueren MAE, Leij-Halfwerk S, Bauer J, Clarke M, Visser M, Volkert D, Bardon L, Gibney E, Corish CA (2019) Manuel consortium. Development and application of a scoring system to rate malnutrition screening tools used in older adults in community and healthcare settings - A ManueL study. Clin Nutr 38(4):1807-1819.

Smith N, Fraser M (2020) Straining the system: novel coronavirus (COVID-19) and preparedness for concomitant disasters. Am J Public Health e1-e2

Trump BD, Bridges T, Cegan J, Cibulsky S, Greer S, Jarman J, Lafferty B, Surette M, Linkov I (2020) An analytical perspective on pandemic recovery. Health $\mathrm{Sec}$

Wells E, Cummings C, Klasa K, Trump BD, Cegan J, Linkov I (2021) Real-time anticipatory response to COVID-19: a novel methodological approach. COVID-19: systemic risk and resilience. Springer Nature. Switzerland AG

WHO (2021) WHO coronavirus disease (COVID-19) dashboard. https ://covid19.who.int/. Accessed 18 Feb 2021. 